\title{
Editorial
}

\section{Digital and virtual world research on brands and marketing development}

Journal of Brand Management (2011) 19, 1-3. doi:10.1057/bm.2011.25

The development of the digital and virtual world continues to take the webscape to an echelon for branding and marketing, such as the development of a brand centre in the second life world demonstrated this revolution. Multinational companies, organisations, practitioners, entrepreneurs, academics and researchers, values the impact and the involvement of the digital and virtual world in their marketing development. Although research on brands, brand management, corporate branding and corporate identity continues to attract the attention of business and marketing academics in reality, research of these topics in the digital and virtual world remains relatively underresearched. This is further evidenced by this special issue calls for paper and thus the opportunity to advance in this research area remains to be imperative.

We received submissions from academics who are based in 37 different countries. The selected papers went through thorough reviews in two stages. Accepted papers were authored by 14 researchers and academics based in Brussel, Canada, Italy, Pakistan, Singapore, Sweden and the United States. These papers included a mixed method empirical study, a quantitative online research, a case study with qualitative data, a longitudinal proposition, conceptual and theoretical reviews.

The first paper by Foster, West and Francescucci explored the use of online social network technologies among young adults (between 18 and 30 years of age) and the brand connections with online customers. It further developed a typology of social media users. A quantitative survey with two qualitative open-ended questions was adopted and pretested with a series of four focus groups before the final administration. The sample of 2471 responses and coded qualitative responses were analysed using exploratory factor analysis, confirmatory factor analysis, cluster analysis and Homogeneity analysis use of alternating least squares or correspondence analysis. Their analyses showed that social media user segments are distinguishable based on their need for information found through various types of online social technologies, as well as their likelihood to engage in interactive participation through these venues. The study aimed to contribute to the body of knowledge about social media behaviours. It also provides both scholars and practitioners with the opportunity to better understand and leverage the benefits of online behaviour, and brand management.

In researching the 'Virtual world brand experience and its impact on real world purchasing behaviour', Gabisch's paper applied an extended theoretical model of planned behaviour by adding three constructs virtual world brand experience, self-image congruence and perceived diagnosticity. Data was collected from users of the 3D virtual world, second life to test the six proposed hypotheses, which was examined 
using hierarchical multiple regression analyses. A marketing research firm has generously collaborated with the author in administering the online survey. Results of the study showed that virtual world brand experience, moderated by self-image congruence and perceived diagnosticity, has an impact on real world purchasing intentions and behaviours. Although 80 per cent of the respondents indicated their primary purpose for using second life was for shopping, entertainment or socializing, 20 per cent reported their primary purpose as business, education or research. The key theoretical contribution of this paper lies in the Theory of Planned Behaviour across multiple marketing channels, in which multichannel effects exist between virtual world brand experiences and real world purchasing decisions. This study has further generated future research opportunities in the area of digital and virtual world research.

A case study by Sasinovskaya and Anderson presented an in-depth qualitative analysis on how a small online information provider turned interactive on the web to help customers participate actively in online bathroom design through social network features and toolkits. The study also aimed to find out the perceived barriers on using the comprehensive provision of online design community. Literatures reviewed in this paper included the brand strengthening, customer involvement in product development and innovation, commitment within the online community and customer experience. The case analysis approach intended to tell a story about a small company's actions over a transformation period of adapting the new technology that Web 2.0. Interviews were conducted with a chief executive officer, a manager, a product developer, a web designer and a retailer. In addition, observations of 3D-design software training for retailers and data from Google analytics added to the data collection. Data was then analysed using a thematic analysis approach with the aid of NVivo software. Although the company continues to be interactive with the community, the case analysis found that the company is somewhat averse to fully utilise the online potential. The paper concluded with a summary of value adding activities for the marketing and product development potential, and the barriers to implement the online design. The barriers are not only because of the lack of resources but also the perceived conservativeness in company strategy.

A holistic longitudinal model of online brand community proposed by Wang, Butt and Wei suggested a link between brand community and perceived social image and identity recognition. The proposed frameworks aimed to describe and explain online brand community members' brand attachment and their distinctive behaviours. To critically evaluate the longitudinal framework of identity and consumer culture theory, 10 propositions proposed included the brand benefits and online brand community, online brand community members' images and brand or community images perceived by other consumers, selfimage congruence and online brand community adopters, online brand community affiliation and the degree of social solidification within the online brand community, which proposed to be related to members' brand attachment (with commitment to the community has a moderator). Subsequent propositions suggested that brand attachment is positively related to the dependence on the online brand community, the intention to disseminate information in the online brand community, the intention to differentiate the online brand community from other communities and the defensiveness for the online brand community. The review underlined that online brand communities are co-markers of branding strategy.

The next paper by Siano, Vollero and Palazzo reviewed the role of online 
consumer empowerment in building online brand reputation (conceptualised as e-reputation) and the social processes of reputation building. The authors argued that empowered online consumers can play the role of mediation between consumers and firm, and in reputation building when they operate within reputation-based systems, opinion platforms, blogs and other social webs. The authors also rationalised three claims for this argument. Theoretical reviews highlighted the potential factors contributing to a firm's e-reputation in its e-marketing concept. Thus, four key research questions and hypotheses were proposed. The first question aimed to find out how does consumer empowerment influence e-reputation building. The second question was to determine the relationship between the determinants of e-reputation and indicators of empowerment in digital contexts (including e-WOM). By means of the frequency and favourability of citations on the most popular Web 2.0, the authors aimed to address the relation of these citations to the building of a firm's e-reputation. Finally, the relation between the use of initiatives that involve opinion leaders/ professionals and the use of certifications/ awards that are communicated via social web applications are related positively and the building of a firm's e-reputation was hypothesised. Though the review did not address the psychological effects of consumer empowerment, the authors' research agenda provided an opportunity to other researchers in online reputation building.

The final paper titled Virtual worlds: A gateway for SMEs towards internationalization by Hassouneh and Brengman provided a review on the value of virtual worlds in the internationalization process of SMEs and proposed a model, which highlighted the reasons for SME to using virtual worlds for internationalization and to grow revenues, accumulate market knowledge and build a brand. This paper started off by describing the internationalization and the Uppsala model. It further reviewed the virtual worlds as a platform and as a strategic tool for entry to the foreign markets. The authors concluded by stating that the prospective transitional effect of virtual world brands moving to the real world.

We hope you enjoy reading this special issue and hope the authors' thoughts and ideas are useful to your practices or to your research.

Lynn L.K. Lim

Roehampton University Business School, Roehampton University, London, UK

T.C. Melewar Brunel Business School, Brunel University, Uxbridge, UK Guest Editors 